\title{
EL NUEVO DERECHO CONSTITUCIONAL A LA IDENTIDAD DE GÉNERO: ENTRE LA LIBERTAD DE ELECCIÓN, EL INCREMENTO DE CATEGORÍAS Y LA SUBJETIVIDAD Y FLUIDEZ DE SUS CONTENIDOS. UN ANÁLISIS DESDE EL DERECHO COMPARADO
}

\section{The New Constitutional Right to Gender Identity:} Adding Choice, Categories or Turning Contents Subjective and Fluid. A Constitutional and Comparative Enquiry

\author{
RUTH RUBIO MARÍN \\ Universidad de Sevilla \\ rrubio@us.es \\ STEFANO OSELLA \\ Max Planck Institut para la Antropología Social \\ osella@eth.mpg.de \\ Cómo citar/Citation \\ Rubio Marín, R. y Osella, S. (2020) \\ El nuevo derecho constitucional a la identidad de género: entre la libertad de elección \\ el incremento de categorías y la subjetividad y fluidez de sus contenidos. \\ Un análisis desde el derecho comparado. \\ Revista Española de Derecho Constitucional, 118, 45-75 \\ doi: https://doi.org/10.18042/cepc/redc.118.02
}

Resumen

Este artículo ofrece un análisis jurídico-constitucional del emergente derecho al reconocimiento de la identidad de género de las personas trans y muestra cómo tal derecho se ha ido fraguando a través del equilibrio entre derechos y principios del constitucionalismo moderno. Tomando como referencia las jurisdicciones de Italia, India, Colombia, y Bélgica (jurisdicciones en las que la jurisprudencia constitucional ha jugado un rol central en la batalla por el reconocimiento del derecho en cuestión), 
el artículo ilustra la variedad de su alcance y establece una taxonomía que distingue entre modelos de categorización por asignación y electivos, binarios y no binarios, y fluidos y no fluidos. El artículo muestra cómo el proceso de creación y control de las categorías de género sigue jugando un rol central aún en aquellos sistemas que aceptan la posibilidad de la reasignación de sexo/género.

\title{
Palabras clave
}

Identidad de género; personas trans; tercer género; binarismo; tribunales constitucionales; derecho constitucional comparado; India; Bélgica; Italia; Colombia.

\begin{abstract}
The article provides a constitutional analysis of the emerging constitutional right to gender recognition of trans people. It shows that the right to gender recognition has been shaped by the balancing of opposing rights and principles inscribed in modern constitutionalism. Focusing on four jurisdictions (Italy, India, Colombia and Belgium) in which constitutional case law has significantly shaped the battle for legal recognition, the article shows the variety of its reach and establishes a taxonomy of classificatory regimes that differentiates between ascriptive and elective; binary/ non-binary and fluid versus non-fluid models of categorization. The article shows how, the process of creating and policing gender boundaries continues to play a central role even in those jurisdictions that have accepted sex reassignment.
\end{abstract}

\section{Keywords}

Gender identity; trans people; third gender; binarism; constitutional courts; comparative constitutional law; India; Colombia; Belgium; Italy. 
I. INTRODUCCIÓN. II. CLASIFICACIONES DE GÉNERO BINARIAS Y HETEROASIGNADAS: EL CASO DE ITALIA. III. CLASIFICACIONES DE GÉNERO NO BINARIAS Y HETEROASIGNADAS: EL CASO DE LA INDIA. IV. LA CLASIFICACIÓN PURAMENTE ELECTIVA AUNQUE AÚN BINARIA: EL CASO DE COLOMBIA V. MANTENIENDO LA ELECCIÓN, SUPERANDO EL BINARIO Y AÑADIENDO FLUIDEZ: EL CASO BELGA. VI. CONCLUSIONES. BIBLIOGRAFIA.

\section{INTRODUCCIÓN}

No es infrecuente que los Estados establezcan categorías jurídicas para clasificar a las personas (Starr, 1992). La definición de categorías es un instrumento habitual del legislador para determinar la posición jurídica de los sujetos de cara a los distintos fines de interés general que persiguen la legislación y las políticas públicas. Uno de los criterios de clasificación legal tradicionalmente más extendido en el mundo, el de sexo/género ${ }^{1}$ — varón/mujer, masculino/femenino - suele definirse en el momento del nacimiento con base en un examen físico del sujeto y ha contribuido a determinar el estatus de derechos y obligaciones en ordenamientos jurídicos tradicionalmente sexuados. Aún hoy seguimos clasificando en función del sexo/género con múltiples propósitos. Así, incluso en aquellos ordenamientos jurídicos que han superado las tradicionales formas de discriminación e inferioridad jurídica de la mujer, el derecho de familia (quién puede casarse o formar una pareja de hecho y con quién), la gestión de los espacios públicos diferenciados

1 En la teoría feminista se solía distinguir entre el sexo —en sentido biológico- - y el género, entendido como la construcción cultural y política del cuerpo sexuado, fundamentalmente para retar la idea de que la biología de las mujeres tuviera que decidir su destino. En las últimas tres décadas esta distinción ha sido a su vez matizada por quienes entienden que también la comprensión del sexo de la persona como un a priori biológico es el resultado de un proceso cultural cuyo objeto es, entre otros, el de preservar la institucionalidad heterosexual dominante (Butler, 1999: 127-174). Es desde esta perspectiva desde la que nos referimos a la noción de "género» o «sexo/ género» en el presente artículo, que no hace sino resaltar que el proceso de asignación de las personas a estas categorías por parte del ordenamiento jurídico obedece a un conjunto de derechos fundamentales e intereses públicos más que a un intento por poner denominación a la esencia biológica de las cosas. 
por sexo (como los baños públicos o los establecimientos carcelarios), la prestación de algunos servicios (como los médico-sanitarios); la participación en determinadas actividades (como las competiciones deportivas); la identificación de las personas de acuerdo con rasgos individuales como los que aparecen en los registros civiles, documentos de identidad o pasaportes, e incluso las políticas de lucha contra la discriminación de sexo, son todos ejemplos de cómo una categorización inequívoca y estable de cada persona con base en el sistema sexo/género sigue, a fecha de hoy, constituyendo una herramienta común de gobernanza.

De hecho, se viene aceptando que algunas de las finalidades con las que se emplean las categorías sexo/género pueden encontrar su fundamento en principios, valores o derechos de rango constitucional. La seguridad jurídica, por ejemplo, depende de la identificación de las personas. La vigilancia y el control policial que también lo hacen están directamente relacionados con la libertad y la seguridad. De igual modo, las medidas en favor de la igualdad del sexo/género históricamente perjudicado, el de las mujeres, incluyendo las medidas de acción positiva (como las cuotas), constituyen la concreción del principio de igualdad sustantiva que recogen muchos textos constitucionales y en algunos ordenamientos aparecen directamente recogidas en la Constitución. También la matriz heterosexual del matrimonio, cada vez más cuestionada, se encuentra a menudo sustentada en preceptos constitucionales.

La aparente simplicidad del sistema clasificatorio tradicional choca, sin embargo, con la complejidad experimentada por las personas trans ${ }^{2}$, quienes,

2 El de personas trans constituye un término general que, en sentido amplio, hace referencia a todas las personas cuya identidad de género no es consistente con las expectativas y códigos normativos asociados al género que les fue legalmente asignado en el momento del nacimiento. El término incluye a las personas transgénero - refiriéndose a aquellas personas que desean vivir de acuerdo con los roles asociados al género que puede considerarse opuesto a aquel asignado al nacer- y a los y las transexuales - aquellos que tienen la intención de someterse, se están sometiendo o hayan sometido a tratamientos de reasignación de sexo, es decir, tratamientos médicos, quirúrgicos u hormonales destinados a adquirir las características físicas asociadas con el género (opuesto) deseado. Este artículo no se centra en el análisis de los derechos de las personas intersexuales entendidas como aquellas que presentan características sexuales biológicas — genitales, gónadas, cromosomas, equilibrio hormonal, etc.- que no corresponden de forma inequívoca y unívoca a las definiciones de masculinidad y feminidad. Intersexualidad e identidad trans son fenómenos distintos, con problemas, demandas, y movimientos sociales también muy diferentes (Dunne, 2018). Ambos ciertamente desafían las tradicionales reglas del sistema sexo/género y cuestionan, por ende, el sistema de categorías jurídicas que 
precisamente por la relevancia de la categorización jurídica, sienten la urgencia de ser reconocidas legalmente en el sexo/género sentido no solo como forma de afianzar un sentimiento de inclusión y pertenencia a la comunidad, sino también para evitar perjuicios socioeconómicos y daños psicológicos en sociedades que siguen siendo, en su mayoría, transfóbicas. En efecto, hace ya tiempo que el colectivo trans viene disputando con éxito la asignación exclusiva e inmutable a las categorías legales de hombre y mujer teniendo fundamentalmente en cuenta la morfología de los genitales al nacer. Con todo, en aquellos ordenamientos que por fin han reconocido la posibilidad del cambio, la estabilización de las identidades de género se ha seguido persiguiendo, por un lado, a través de la estricta vigilancia de las fronteras entre categorías (sometiendo las transiciones a procesos altamente medicalizados para garantizar la coincidencia del sexo legal con los rasgos físicos que se entendían propios de cada sexo), y, por otro, limitando las opciones al binomio hombre-mujer (Spade, 2015; Dunne, 2017), siendo aún pocas las jurisdicciones que reconocen un tercer género ${ }^{3}$. Entre las transformaciones tradicionalmente exigidas encontramos tanto las quirúrgicas como las hormonales, siendo igualmente frecuente un sistema de evaluación psiquiátrico capaz de certificar la necesidad y permanencia del cambio de sexo. Es así cómo el ordenamiento jurídico no ha dejado de definir lo que, para el derecho, constituye un "verdadero" hombre o una "verdadera» mujer, atendiendo a sus características corporales (genitales, pechos, vello o estructura corporal), su comportamiento (estilo de vestir, modales, preferencias estéticas) y, a veces, también, a su orientación sexual. Además, la expectativa común ha venido siendo que dichas transformaciones y las conquistadas características del nuevo género fueran no solo evaluables externamente, sino, idealmente, también, de carácter permanente.

sobre estas reglas se asienta. Para un adecuado análisis de la intersexualidad en sus aspectos sociolegales en Espańa, véanse Arroyo Gil (2019), Lauroba Lacasa (2018) y García López (2015).

3 Además de la India, tribunales supremos/cortes constitucionales han reconocido la existencia de géneros no binarios en las siguientes jurisdicciones: Bélgica (Cour Constitutionelle, 19 junio 2019, n. 99/2019, https://bit.ly/2vJVtf2); Austria (Verfassungsgerichtshof, 15 junio 2018, G-77/2018-9, https://bit.ly/2TKtJ1H); Alemania (BVerfG, 1 BvR 2019/16 — Rn [1-69], https://bit.ly/3awlBJ4); Nepal (Sunil Babu Pant and Others v. the Government of Nepal and Others [2008] 1 Writ no 9172064 BS [2007 AD] 2 NJALI [2008] 261); Pakistán (Dr. Muhammad Aslam Khaki \& Almas Shah v. Senior Superintendent of Police [Operations] Rawalpindi \& Others [2009], Human rights case no. 63 of 2009), y Australia (NSW Registrar of Births, Deaths and Marriages v Norrie [2014] HCA 11 [2 April 2014]). 
Por todo ello, la reivindicación del derecho al reconocimiento de la identidad de género y a la consiguiente reasignación de sexo/género han ampliado en los últimos tiempos su campo de pretensiones para abarcar no solo la posibilidad misma del cambio, sino también la expansión de las categorías entre las que elegir, así como el hecho de que la elección dependa exclusivamente de la autodeterminación, como reconocen, a fecha de hoy, los estándares internacionales de buenas prácticas ${ }^{4}$. Este cuestionamiento de los regímenes de clasificación de género en cada vez más jurisdicciones a nivel global ha dado lugar a una jurisprudencia que obliga a articular de forma explícita, en vez de presuponer, la confluencia de (así como la tensión entre) distintos derechos e intereses que subyacen al sistema dominante de clasificación de sexo/género, traduciéndose, en algunos casos, en la exigencia de reformas legales. Entre nosotros, la doctrina (Elvira Perales, 2013: 7-10; Salazar Benítez, 2015) y el propio Tribunal Constitucional han reconocido el anclaje constitucional del derecho a la reasignación (en este caso concreto de los menores con suficiente madurez y que se encuentren en una situación estable de transexualidad), cuanto menos, en el libre desarrollo de la persona (art. 10.1) y en el derecho a la intimidad personal (art. 18.1) . No podemos excluir que, de no actuar el legislador para eliminar el resto de rasgos patologizadores de nuestra legislación o de aquellos que, en todo caso, limitan aún la autodeterminación, esta materia vuelva a ser objeto de litigio constitucional en un futuro próximo ${ }^{6}$.

Con todo, hasta la fecha, el debate transnacional en torno al reconocimiento de la identidad de género se ha desarrollado principalmente en el

4 Véase, por ejemplo, el principio 31 de los Principios de Yogyakarta+10 — Principios adicionales y obligaciones estatales sobre la aplicación del derecho internacional de los derechos humanos en relación con la orientación sexual, la identidad de género, la expresión de género y las características sexuales para complementar los Principios de Yogyakarta (Ginebra, 10 de noviembre de 2017).

5 Véase STC 99/2019, de 18 de julio de 2019, https://bit.ly/2v43s6q. Este artículo se centra en el análisis de los derechos de las personas trans adultas. Sin embargo, es importante mencionar que también los niños trans pueden tener la necesidad - y el derecho- al reconocimiento de su identidad de género (véanse, al respecto Benavente Moreda, 2018; Burgos García, 2016), como reconoció, con alguna cautela, nuestro Tribunal Constitucional en la sentencia citada.

6 De hecho, los recurrentes en la STC 99/2019 habían solicitado que también se declarasen inconstitucionales las exigencias impuestas por el art. 4 de la Ley 3/2007 (diagnóstico médico y tratamiento hormonal) entendiendo que, al constituir una heteroasignación de la identidad sexual, se lesiona la dignidad de la persona transexual. El Tribunal estima, sin embargo, que la pretensión queda fuera del objeto procesal del recurso y no se pronuncia al respecto (FJ 3). 
ámbito de los derechos humanos (O’Brien, 2015; O'Flaherty, 2015), permaneciendo su dimensión constitucional relativamente inexplorada sobre todo por lo que hace a una perspectiva comparada. Este artículo pretende contribuir a colmar este vacío y muestra cómo, en términos constitucionales, la delimitación del derecho a la identidad de género ha resultado hasta la fecha de un equilibrio entre distintos derechos y valores de relevancia constitucional en distintos sistemas constitucionales. En concreto, el artículo analiza la jurisprudencia y su evolución en cuatro jurisdicciones (Italia, India, Colombia y Bélgica). Los casos seleccionados sugieren, además, la posibilidad de un camino evolutivo hacia un derecho a la identidad de género basado meramente en la autodeterminación y capaz de superar la definición objetiva, el binarismo y la rigidez, en aras de un entendimiento de la identidad de género y de la identidad sexual como algo subjetivo, complejo y fluido.

A la hora de clasificar los sistemas legales de definición de género, el artículo se basa en una taxonomía que se centra tanto en las fronteras que vigilan los contenidos de los distintos géneros reconocidos ( $\mathrm{y}$ en el aparato encargado de supervisarlas) como en el número total de géneros reconocidos y la posibilidad de alternancia o cambios a lo largo de la vida de la persona. En concreto, distinguimos aquellas jurisdicciones en las que la clasificación de género sigue siendo mayormente por heteroasignación, en oposición a aquellas jurisdicciones en las que dicha clasificación se ha vuelto cada vez más electiva y subjetiva. Los regímenes de género por heteroasignación son no solo aquellos que no permiten al individuo el cambio del sexo/género asignado en el nacimiento, sino todos aquellos que, aun permitiendo el cambio, tratan de fijar los confines de las categorías reconocidas mediante criterios de clasificación objetivos y predeterminados, lo que hace que las categorías descansen en último término en un sistema de evaluación o certificación externa. Los regímenes de género electivos, por el contrario, se basan principalmente en la autodeterminación y obedecen a un entendimiento subjetivo de las categorías. El alcance pleno de la autodeterminación en la materia completa la taxonomía añadiendo regímenes que se apartan del tradicional sistema dual (hombre/mujer) y regímenes que permiten (en vez de prohibir o inhibir) las mutaciones diacrónicas.

El doble objetivo que inspira el artículo, el de describir la evolución jurisprudencial de los confines del derecho a la identidad de género y el de proporcionar, a la luz de las experiencias descritas, un marco analítico para repensar las clasificaciones jurídicas de género, ha condicionado la elección de jurisdicciones objeto de análisis. Así, obviando aquellos sistemas en los que la identidad de género y el cambio de sexo no han sido reconocidos aún (o lo han sido a nivel meramente legislativo), hemos seleccionado casos en los que el derecho a la identidad de género ha sido el producto de una evolución 
jurisprudencial constitucional que ha puesto, sin embargo, distintos grados de énfasis en distintos derechos y valores constitucionales. El siguiente epígrafe aborda el caso italiano, jurisdicción que legitima el sistema binario y la asignación heterónoma e ilustra el conflicto que surge entre los derechos fundamentales del individuo que solicita la reclasificación y la garantía institucional de la familia heterosexual. El tercer epígrafe, centrado en la India, jurisdicción que, por mandato constitucional, se ha apartado del sistema binario, ejemplifica la tensión entre el reconocimiento de un derecho fundamental a la identidad de género que admita un tercer género y el principio constitucional de la igualdad articulado a través de mecanismos de no discriminación e inclusión social que dependen de la posibilidad de identificar a los colectivos minoritarios beneficiarios. Le sigue el análisis de la experiencia de Colombia, cuyo Tribunal Constitucional, valiéndose de nociones cada vez más fuertes de autonomía, ha venido progresivamente priorizando la autodefinición, hasta llegar a imponer un sistema clasificatorio de carácter puramente electivo, aunque, de momento, aún binario. El caso belga se describe por último y representa una lectura constitucional del derecho en cuestión que pone pleno énfasis en la autonomía personal en relación con la vida privada y familiar, así como en el principio de igualdad y derecho a no ser discriminado para defender la necesidad constitucional de un sistema de género que sea puramente electivo, abandone el régimen binario y permita, además, la fluidez en el tiempo. Concluimos con una breve discusión respecto a las confluencias emergentes, las variaciones restantes, y los posibles caminos evolutivos, destacando sus implicaciones teóricas para el futuro sistema de clasificación legal de género.

\section{CLASIFICACIONES DE GÉNERO BINARIAS Y HETEROASIGNADAS: EL CASO DE ITALIA}

Italia, a fecha de hoy, no reconoce aún el matrimonio entre personas del mismo sexo, siendo su posible conformidad constitucional todavía objeto de un amplio debate doctrinal (Cartabia, 2011; Pezzini, 2010). Las uniones civiles entre personas del mismo sexo fueron legalizadas solo en 2016 , de acuerdo con un régimen que comporta aún ciertas limitaciones con respecto al régimen matrimonial. No resulta sorprendente, por tanto, que la preocupación por preservar la matriz heterosexual de la familia haya estado en el centro del debate desde los primeros casos de reconocimiento de la identidad de género.

Ley 11 mayo 2016, núm. 76. Todas las leyes italianas se pueden consultar en: www.normattiva.it. 
Las primeras decisiones, que se remontan a los años setenta, se limitaban a rechazar las solicitudes de reasignación sexual independientemente de que provinieran de personas que se hubieran sometido a cirugías de reasignación. En su denegación, los tribunales italianos interpretaban la ley sobre el estado civil de las personas entendiendo que el sexo, en sentido puramente biológico, debía quedar fijado en el momento del nacimiento, previo examen físico, y de forma inmutable. La posibilidad de una reclasificación se percibía, en esencia, como algo contrario a los principios del derecho de familia. Se trataba fundamentalmente de evitar que las personas pudiesen entablar relaciones sexuales y afectivas con personas del mismo «sexo biológico» por error ${ }^{8}$. De esta forma, cuando en 1979 se recurre la constitucionalidad de la ley del estado civil por no reflejar los reclamos de las personas transexuales, el Tribunal Constitucional italiano se niega a proporcionar remedio alguno y se limita a invitar al legislador a que busque una solución capaz de atender a las necesidades legítimas del colectivo afectado, eso sí, sin dejar de tener en cuenta los límites impuestos por el matrimonio, definido por la Constitución italiana (en su art. 29) como fundamento de la familia en tanto que «sociedad natural»?

El legislador italiano recogería el guante y, empatizando con la situación de las personas transexuales, a las que se refiere en la exposición de motivos en términos de vulnerabilidad y fragilidad (Voli, 2018), responde adoptando la ley 164 de 1982, válida, en lo que nos atañe, hasta la fecha de hoy ${ }^{10}$. Dicha ley otorga el derecho a la reclasificación siempre que se dé con posterioridad a la modificación de las características sexuales, sin mayor especificación de lo que haya de entenderse por tal, poniendo en marcha un mecanismo de supervisión médico y judicial ${ }^{11}$. La ley prevé que los tratamientos sean administrados por médicos, debiendo ser las cirugías de reasignación previamente autorizadas por un juez ${ }^{12}$, quien posteriormente se encargará también de comprobar

8 Corte di Cassazione (Cass.), Sección I, 3 diciembre 1974, n. 3948, Diritto di Famiglia e delle Persone, 1974, 127. Véanse también: Corte di Appello de Bolonia, 23 enero 1970, en Giurisprudenza Italiana, 1971, I, 2, 61; Tribunale de Pisa, 9 marzo 1970, en Giurisprudenza Italiana, 1971, I, 2, 61, y Cass., 13 junio 1972, n. 1847, en Foro Italiano, 1972, I, I, 2399.

9 Corte Costituzionale (Corte Cost.), 1 agosto 1979, n. 98. Todas las sentencias de la Corte Constitucional de Italia se pueden consultar en https://bit.ly/2Twm4Wa.

10 Algunos cambios procedimentales en el proceso de reconocimiento de género han sido introducidos a través del decreto legislativo (d. lgs.) 161 de 2011. No obstante, los prerrequisitos para la reclasificación no se han modificado.

11 Art. 1, legge (l.) 164 de 1982. Para una discusión general de la ley, véase Lorenzetti (2013).

12 Art. 3, 1. 164 of 1982, ahora art. 31 d. lgs. n. 150 of 2011, en términos idénticos. 
que la transformación física del sujeto es bastante como para garantizar de forma suficiente la transición al nuevo sexo. En otras palabras, el cambio legal de sexo se hace posible, pero el género no deja de concebirse como una condición definible y evaluable por expertos con base en estándares objetivos.

Por otro lado, la nueva ley incorpora alguna de las preocupaciones en torno a la regulación de la institución matrimonial. Así, aunque la ley no establece el celibato como condición necesaria para la reasignación de género, sí prevé que el matrimonio anterior —el cual, después de la transición, pasaría a ser un matrimonio entre personas del mismo sexo- queda automáticamente disuelto, quedando la persona libre para casarse con una persona del sexo contrario al adquirido ${ }^{13}$. Solo de forma reciente, el Tribunal Constitucional ha rectificado sosteniendo que imponer el divorcio de forma automática a la persona transexual reclasificada constituye una violación de sus derechos fundamentales ${ }^{14}$, aunque, curiosamente, no una violación del derecho al matrimonio (que sigue siendo una institución heterosexual) y ni siquiera del derecho a la vida familiar, sino una violación del más genérico derecho a «vivir juntos como pareja» en cuanto que aspecto fundamental del libre desarrollo de la personalidad humana al amparo del art. 2 de la Constitución ${ }^{15}$.

A pesar de las precauciones de la ley de 1982 por no alterar el sistema de relaciones conyugales, la ley generó resistencias, sobre todo por parte de la judicatura. Así, en lo que resultaría una infructuosa cuestión de inconstitucionalidad planteada por el Tribunal de Casación al Tribunal Constitucional ${ }^{16}$, aquel advertía acerca de las posibles consecuencias de la nueva regulación tanto para la estructura heterosexual de la familia como para la función procreadora del matrimonio ${ }^{17}$. Salvando la constitucionalidad de la ley 164 , el Tribunal Constitucional italiano dictaría en 1985 la sentencia que, a fecha de hoy, sigue siendo la piedra angular del sistema italiano sobre reclasificación. Se trata de una sentencia que mezcla compasión y pragmatismo, y que, en esencia, patologiza la

13 Art. 4, 1. 164 of 1982.

14 Corte Cost., 11 giugno 2014, n. 170.

15 Ibid., [5.2] (fundamentos jurídicos). Véase también la sentencia Hämäläinen $v$ Finland del TEDH de 17 de julio 2014, que considera que Finlandia no había sobrepasado sus obligaciones en virtud del art. 8 de la Convención porque concedía a las personas trans el derecho a «convertir» su matrimonio en una unión civil. Las sentencias del Tribunal Europeo de Derechos Humanos están disponibles en: https://bit. ly/3cAQZYV.

16 Cass., 15 abril 1983, ordinanza n. 783, en Gazzetta Ufficiale della Repubblica Italiana (29 febbraio 1984), 60, 1755, 1759 (It.).

17 Ibid., 1760. 
condición trans ${ }^{18}$. En ella, el Tribunal alega razones de solidaridad hacia las personas pertenecientes a este colectivo para defender la conveniencia de un sistema de reclasificación de género, eso sí, acompañado por la (presuntamente) deseada transformación de las características sexuales primarias y secundarias mediante tratamiento hormonal y cirugía ${ }^{19}$. Es así como el Tribunal acaba anclando el derecho a la reclasificación principalmente en el derecho fundamental a la salud consagrado (art. 32) ${ }^{20}$, sin dejar de reconocer, por otro lado, la creciente centralidad otorgada por el ordenamiento jurídico a valores tales como la dignidad y la libertad, valores que el Tribunal entiende son especialmente merecedores de protección cuando se refieren a minorías discriminadas ${ }^{21}$, sugiriendo la posibilidad de que el derecho a la identidad de género se entendiera abarcado por el derecho al libre desarrollo de la personalidad consagrado en el art. 2 de la Constitución ${ }^{22}$. Consideraciones pragmáticas, y no solo razonamiento de principios, permean una decisión que reconoce que, al fin y al cabo, la ley no hace más que regular un fenómeno que ya existe y que ya está afectando, en cierta medida, a la estructura heterosexual de la familia ${ }^{23}$. Desde esta óptica, recuerda el Tribunal que asegurar «la coincidencia entre el sexo que aparece en registros públicos y la apariencia física [de la persona transexual operada] solo puede tener un efecto favorable para la transparencia de las relaciones sociales, y, por tanto, para la seguridad jurídica» ${ }^{24}$.

Esta jurisprudencia encontraría en 2002 el aval del Tribunal Europeo de Derechos Humanos ${ }^{25}$. Con fecha reciente, sin embargo, y en respuesta a la lucha del colectivo trans por reducir o eliminar las condiciones para la reclasificación, ha venido limitando los requisitos que se pueden válidamente exigir, reconociendo, por ejemplo, que el requisito de la esterilización viola el derecho a la vida privada consagrado bajo el art. 8 de la Convención, y que, por tanto, no puede justificarse bajo ninguna circunstancia en una sociedad democrática ${ }^{26}$. Esta

\footnotetext{
Corte Cost., 6 mayo 1985, n. 161 (It.).

Ibid., [4] (fundamentos jurídicos).

Ibid., [10] (fundamentos jurídicos).

Ibid.

22 Ibid., la identidad «sexual» se define como "aspetto e fattore di svolgimento della personalità umana» (Dogliotti, 1987: 242).

23 Corte Cost. (n. 21) [12] (fundamentos jurídicos).

24 Ibid., [10] (fundamentos jurídicos).

25 Véase Christine Goodwin v. the United Kingdom, App No. 28957/95 (TEDH, 11 de julio de 2002).

26 Véanse los asuntos en: Garçon et Nicot v. France, Apps. No 79885/12, 52471/13, 56596/13 (TEDH, 8 de mayo de 2017), y Y.Y. v. Turkey App no 14793/08 (TEDH,
} 
evolución jurisprudencial ha tenido sus efectos en Italia, donde en 2015 el Tribunal Constitucional ${ }^{27}$, precedido por el Tribunal de Casación ${ }^{28}$, finalmente reconoce que la cirugía de reasignación de sexo no puede seguir exigiéndose como condición previa a la reclasificación. Sin dejar de referirse a las tensiones que resultan del reconocimiento de los derechos fundamentales de las personas trans (especialmente sus derechos a la identidad personal ${ }^{29}$ y la salud ${ }^{30}$ ), por un lado, y el interés estatal por garantizar la seguridad jurídica ${ }^{31}$, por otro, la sentencia descansa sobre la idea de que, aunque deje de exigirse la cirugía de reasignación sexual, sigue siendo necesaria una transformación total de las características de comportamiento, psicológicas y físicas en un proceso sujeto a un estricto control judicial ${ }^{32}$ (Rubio-Marín y Osella, 2016; Patti, 2016). En otras palabras, el género corporal tiene que seguir correspondiendo de forma inequívoca con el género legal, conclusión que una nueva decisión del Tribunal Constitucional del ańo 2017 no hizo sino confirmar ${ }^{33}$ (Lorenzetti, 2018).

En conclusión, el sistema de clasificación de género italiano resulta ser un sistema binario, medicalizado y judicializado, que ha evolucionado, desde la perspectiva constitucional, a partir del equilibrio entre el derecho de las personas trans al reconocimiento de su identidad — anclado, primero, en la salud y, más tarde, también en la autodeterminación- y el interés por preservar la matriz heterosexual del matrimonio constitucionalmente arraigada. Se trata de un sistema de clasificación por heteroasignación porque, aunque admite la transición, la deja en última instancia fuera del dominio soberano de las personas interesadas, a quienes solo se les ofrece la opción entre someterse a las condiciones que establece la ley o permanecer en el género asignado al nacer. Los requisitos físicos y comportamentales esenciales para la reasignación han ido cambiando a lo largo del tiempo, siguiendo la evolución de los estándares de derechos humanos, estándares que hoy en día consideran la esterilización forzosa y la cirugía de reasignación sexual intromisiones ilegítimas. El sistema sigue, sin embargo, descansando sobre una

10 de marzo de 2015). Sobre el cambio de nombre, véase S.V. v Italy, App No 55216/08 (TEDH, 11 de octubre de 2018).

27 Corte Cost., 21 de octubre de 2015, n. 221 (It.).

28 Cass., sez. I, 20 de julio de 2015, n. 15138, disponible en www.articolo29.it.

29 Art. 2 Cost. y 8 CEDH.

30 Art. 32 Cost.

31 Corte Cost. (n 30) [4.1.] (fundamentos jurídicos).

32 Ibid.

33 Corte Cost., 20 junio 2017, n. 180, [5.1.] y [5.2.] (fundamentos jurídicos). 
noción de feminidad y masculinidad «mínima»o «esencial», constitutiva del sujeto, esencia por la que siguen velando, de forma conjunta, tanto médicos como jueces.

\section{CLASIFICACIONES DE GÉNERO NO BINARIAS Y HETEROASIGNADAS: EL CASO DE LA INDIA}

Las personas con disconformidad de género han sido tradicionalmente reconocidas en la cultura India, donde la «otredad» sexual está fuertemente entrelazada con la historia religiosa y política del país (Reddy, 2005: 27; Boyce, 2015). Y aunque la amplia constelación de identidades de género presentes en la India y su análisis exceden el objeto de este artículo, podemos mencionar, como ejemplo paradigmático, a l@s hijras, grupo social de personas nacidas biológicamente hombres (o intersexuales) que pueden adquirir la identidad de tercer género (aunque también la identidad femenina), formando una comunidad propia basada en prácticas simbólicas, religiosas y rituales comunes (Reddy, 2005: 54) . $^{34}$.

Bajo el dominio británico, el colectivo de individuos pertenecientes al tercer género, los "eunucos», como, de forma genérica, se les llamaba, quienes, hasta entonces, habían gozado de un cierto estatus social, fueron perseguidos y hostigados. La llamada Ley de Tribus Criminales de 1871 criminalizaba su existencia, ordenando su registro y control e imponiendo severas limitaciones a su capacidad jurídica, lo que en la práctica los condenaba a la mendicidad y prostitución (Boyce, 2015: 20). Su persecución subsistió más allá de la revocación de la ley, a través de la criminalización del sexo oral y anal bajo el Código Penal indio, código que la policía usaba con frecuencia para acosar tanto a trans como a homosexuales (Narrain, 2009: 466). Solo a finales del siglo xx se empezó a relajar la persecución del colectivo trans, pero su falta de reconocimiento legal ha continuado provocando su exclusión de los servicios básicos del Estado de bienestar, como la educación, la atención médica, las tarjetas de racionamiento de alimentos o el empleo, como si de «intocables» se tratara.

Aunque el Gobierno indio reconoció la posibilidad de registrarse como «transgénero» en el pasaporte en $2005^{35}$, la categoría del «tercer género»,

34 Otros ejemplos pueden ser l@s y l@s aravanis_l@s más similares a l@s hijras, propios del estado de Tamil Nadu_y l@s jogins, que visten con atuendos femeninos y se parecen en general a l@s hijras, salvo que son hindúes y no musulman@s.

35 Dicho registro dependía de una declaración jurada por parte del demandante y de un certificado médico que confirmara la cirugía de cambio de sexo (Instructions 
como categoría específica, surgió a nivel constitucional solo en 2014, de la mano de la famosa sentencia del Tribunal Supremo Autoridad del Servicio Judicial Nacional contra la Unión de la India (conocida, por sus iniciales en inglés, como caso $N A L S A)^{36}$. La Corte contaba con el precedente de la Ley de Derechos de las Personas Transgénero del estado de Tamil Nadu, que desde unos ańos antes permitía certificar a personas aravani - como pertenecientes al tercer género- proporcionándoles los documentos de identificación necesarios para que pudieran acceder a las prestaciones sociales para ell@s destinadas (Chakrapani, 2012: 22). El proceso de certificación dependía de comités evaluadores que incluían médicos y miembros de la comunidad trans y se basaba en un conjunto de criterios evaluables externamente, incluyendo los rasgos físicos de la persona, así como su reconocimiento social, tomando en cuenta, entre otros, si la persona estaba castrada, vivía integrada en la comunidad aravani o se vestía con atuendos de mujer.

En el caso NALSA el Tribunal Supremo reconoce por fin el derecho a la reclasificación de género y el necesario reconocimiento del tercer género. El demandante, el Servicio Legal Nacional, institución encargada de proporcionar asistencia legal gratuita a los sectores sociales más deprimidos, reclamaba el reconocimiento de la identidad de género y la adopción de medidas específicas para garantizar la plena participación social y cultural y para corregir las restricciones a las que se enfrentaba el colectivo trans en su acceso a la educación, la atención médica y, en general, a los lugares públicos. La decisión resultante reconoce la existencia del derecho a la identidad de género, sustentada en varios derechos fundamentales, entre ellos el derecho a la vida y libertad personal y, en conexión con ambos, a la dignidad (art. 21), la igualdad (arts. 14, 15 y 16) y la libertad de expresión (art. 19 [1] a), entendiendo que tales derechos amparan el derecho a ser reconocido como perteneciente a un género de elección, ya fuera este el masculino, el femenino, o un tercer género.

En su razonamiento, el Tribunal reconoce que la falta de reconocimiento legal es la causa principal de la discriminación extrema que sufren las personas trans y que, por tanto, entra en conflicto con la igual protección de la ley (art. 14) ${ }^{37}$, así como con las cláusulas contra la discriminación contenidas en la Constitución india (arts. 15 y 16), que incluyen el sexo entre los criterios de dudosa legitimidad, y que la Corte interpreta, debe abarcar

for Filling a Passport Application Form, 38-39, disponible en: www.passportindia. gov.in).

36 National Legal Services Authority v Union of India [NALSA], (2014) 5 S.C.C. 438 [5]

(India), disponible en: https://main.sci.gov.in/judgments.

37 NALSA [55]. 
también la «identidad de género» ${ }^{38}$. Además, el Tribunal reconoce que la protección igualitaria genera la necesidad de adoptar medidas de acción positiva previstas de forma genérica en favor de los colectivos desfavorecidos en la Constitución ${ }^{39}$. La libertad de expresión (art. 19 [1] a), argumenta el Tribunal, también protege la identidad de género, siendo las personas transgénero libres de manifestar su personalidad a través de su forma de vestir, hablar, sus acciones y, en general, su comportamiento ${ }^{40}$. Centrales para el reconocimiento del derecho a la identidad de género resultan también el derecho a la vida y la libertad y la dignidad inherente a ambos, derivados de la cláusula del debido proceso (art. 21). En efecto, según el Tribunal, la dignidad abarca el «poder expresarse de manera diversa, moverse con libertad y entremezclarse con otros seres humanos $»^{41}, y$, por tanto, tiene que abarcar la autodeterminación de género, que es "parte integral de la autonomía y la auto-expresión personal y cae dentro del ámbito de la libertad personal que garantiza el Artículo 21 de la Constitución de la India» ${ }^{42}$.

En una crítica poscolonial velada, el Tribunal contrasta la tradicional tolerancia de la diversidad de género en la cultura india con la moral victoriana británica que, según el Tribunal, vino a edulcorarla. Fue la imposición de valores no indios en la sociedad local, argumenta el tribunal, lo que acabó relegando a las personas con disconformidad de género a la pobreza y la marginación ${ }^{43}$. La decisión concluye con una lista de directrices dirigidas al Gobierno central y estatal para garantizar el reconocimiento de las identidades trans, corregir las desventajas experimentadas por el colectivo y facilitar la toma de consciencia por parte de la sociedad ${ }^{44}$.

A pesar del celebrado reconocimiento de la categoría del tercer género, las tensiones entre el modelo de clasificación por heteroasignación y el puramente electivo permean la decisión del Tribunal. Por un lado, las directrices contenidas en la decisión parecían apuntar hacia la autodeterminación y la subjetividad. Así, el Tribunal Supremo ordena que l@s hijras, y todas las personas que no encajen dentro del binomio de género dominante, sean tratad@s y reconocid@s legalmente como "tercer género", pidiendo al legislador que regule dicha categoría sobre todo con la finalidad de proteger los derechos de las personas afectadas. El

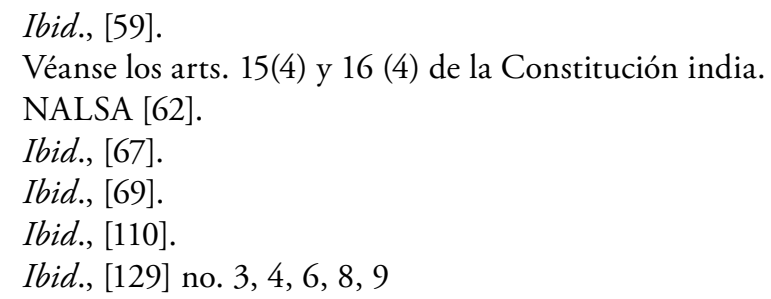


Tribunal también dictamina que todas las personas transgénero tienen derecho a decidir libremente su condición de hombre, mujer o tercer género, enfatizando así el elemento de la autonomía individual ${ }^{45}$. En el mismo sentido, el Tribunal invalida algunos requisitos médicos, sosteniendo, en concreto, que la cirugía de cambio de sexo como condición previa resulta inmoral e ilegal ${ }^{46}$.

Por otro lado, muchos aspectos de la decisión indican que, a pesar de todo, la superación del binario de género es limitada y que sigue prevaleciendo constitucionalmente un enfoque del reconocimiento de género por heteroasignación. En efecto, el Tribunal especifica el interés público que subyace a la pervivencia del binario de género en el sistema jurídico de la India mencionando tanto el derecho de familia (en concreto, el matrimonio, la adopción y la herencia) como el derecho penal, y la administración del Estado del bienestar ${ }^{47}$, sin aportar pistas acerca de cómo exactamente se espera que esas expresiones binarias en el ordenamiento convivan con el reconocimiento de un tercer género como aquel al que obliga la sentencia. Además, el Tribunal aboga por la introducción del requisito de un "test psicológico" poco especificado (y que suele interpretarse como una evaluación psiquiátrica capaz de diagnosticar la disforia de género) (Dutta, 2014: 232), test que habría de sustituir la evaluación física como mecanismo para identificar indicios tangibles de la condición trans ${ }^{48}$. Por último, y quizá de manera más determinante, la narrativa general de la decisión se basa en la existencia de identidades de género discernibles a las que cabe adscribir características específicas - físicas, psicológicas y comportamentales - características que, por tanto, pasan a conformar al sujeto transgénero $\mathrm{y}$, sobre todo, al sujeto perteneciente al tercer género, categoría que el Tribunal asume como la naturalmente deseada por l@s hijras y otros trans, a pesar de que, de hecho, algun@s dicen sentirse mujeres (op. cit. $)^{49}$. El desarrollo legislativo posterior parece confirmar la dependencia de criterios de clasificación objetivos como complemento a la autodeterminación individual ${ }^{50}$.

\footnotetext{
Ibid., [129] no. 2.

Ibid., [129] no. 5.

Ibid., [49], [75].

Ibid., [34].

49 El entendimiento de la categoría de tercer género que maneja la sentencia ha sido también criticado por su carácter netamente identitario y por lo que muchos entienden que constituye un intento de «hinduizar» la categoría, negando sus elementos en la tradición musulmana en un proyecto al que algunos se refieren como «homonacionalismo» (Loh, 2018).

50 El Transgender Persons (Protection of Rights) Act 2019, por un lado, afirma que las personas transgénero pueden obtener un certificado de identidad como transgénero
} 


\section{LA CLASIFICACIÓN PURAMENTE ELECTIVA AUNQUE AÚN BINARIA: EL CASO DE COLOMBIA}

Bajo la creciente preponderancia de aquellos derechos fundamentales que amparan la dignidad y la autonomía individual, un sistema de clasificación de género por heteroasignación puede transformarse, con el tiempo, en uno de carácter puramente electivo, es decir, en un sistema basado únicamente en la autopercepción, o el género sentido en el fuero interno. Sobra decir que esto puede transcurrir por vía legislativa sin que el debate llegue a dirimirse en sede constitucional. Sin embargo, el cambio puede también venir forzado por una jurisprudencia constitucional que limite las opciones del legislador a la hora de definir el sistema de clasificación. Es el caso de Colombia, donde, al igual que en Italia y la India, el constitucionalismo ha desempeñado un papel fundamental en la materia, en este caso desde mediados de los ańos noventa $^{51}$. No resulta sorprendente que dicha evolución se haya desarrollado en paralelo a la evolución del derecho de familia colombiano y a la creciente superación de su heteronormatividad. Si, a mediados de la década de los noventa, la Corte Constitucional empieza a adoptar una serie de decisiones destinadas a proteger a las personas LGBTI frente a la discriminación, es en 2016 cuando finalmente reconoce el derecho de las parejas del mismo sexo al matrimonio igualitario ${ }^{52}$.

La opción de un tercer género, sin embargo, no existe en la legislación colombiana, por lo que el sistema sigue siendo estrictamente binario. Solo para aquellos casos de intersexualidad en los que la anatomía sexual presenta una ambigüedad tan severa que la asignación del género en el momento del nacimiento resulta casi imposible la Corte Constitucional ha reconocido el derecho a registrarse sin definir el sexo ${ }^{53}$. Por lo demás, la Corte ha entendido

y afirma el derecho de las personas a ser reconocid@s en su propia y autopercibida identidad de género. Sin embargo, la ley también especifica que el reconocimiento de la identidad de género queda sujeto a la producción de las pruebas y documentos que el magistrado del distrito tenga a bien requerir (sin mayor especificación) (art. 5). Además, la ley no es clara sobre el requisito de la cirugía de asignación de género previo al reconocimiento como hombre o mujer de la persona trans (art. 7). La ley está disponible en: https://bit.ly/2TF9Rgo.

51 Para una reconstrucción completa del desarrollo de los derechos LGBTQI en Colombia, véanse Encarnación (2016) y Lemaitre (2009).

52 Véase CC, Sala Plena, 28 de abril de 2016, Sentencia SU-214/2016. Todas las sentencias de la Corte Constitucional están disponibles en: https://bit.ly/2PWq53R.

53 CC, Sala Segunda de Revisión, 16 de julio de 2013, Sentencia T-450A/13. 
que el estado civil de las personas tal y como aparece en el registro y con referencia al sexo de la persona tiene por función identificar a la persona y determinar su estatus jurídico y es, por tanto, esencial en un Estado que no puede proveer a sus ciudadanos a menos que sepa de su existencia ${ }^{54}$, y que tiene la obligación de garantizar la seguridad de las relaciones jurídicas ${ }^{55}$. En concreto, la Corte ha reconocido el carácter esencial de la clasificación de género para el derecho matrimonial - en una decisión posterior al reconocimiento legal de las parejas del mismo sexo pero que antecedió al reconocimiento del matrimonio igualitario - pero también para la inclusión y la protección especial de las mujeres y las madres, asumiendo así la relevancia general de las categorías de género en el sistema constitucional ${ }^{56}$.

En materia de reasignación de género ${ }^{57}$, es la Sentencia T-504/94 de la Corte Constitucional colombiana la que marca el punto de partida con respecto a la reasignación ${ }^{58}$. Hasta entonces, se venía permitiendo la reclasificación de género de acuerdo con el procedimiento general para modificar el estado civil de las personas, procedimiento que requería de autorización judicial59. En 1994 la Corte Constitucional avala esta intervención judicial al entender que la reclasificación de género no podía entenderse como la mera corrección de un error técnico, y, por tanto, requería una evaluación por parte de un juez. Al tratarse de un dato legal de naturaleza física, el sexo de la persona no podía depender de la autoevaluación individual, siendo de carácter objetivo ${ }^{60}$. Esta posición de partida, sin embargo, evolucionaría pronto. En 2015 la Corte abandona de forma clara su doctrina y declara constitucionalmente obligado un proceso notarial para el cambio de sexo, por ser este último más informal, menos costoso y engorroso que el proceso judicial ${ }^{61}$ (Bernal Crespo, 2018).

54 Ibid., [4.2.2]

55 CC, Sala Primera de Revisión, 13 de febrero de 2015, Sentencia T-063/15, [II.7.2.6].

56 CC, Sala Segunda de Revisión, 16 de julio de 2013, Sentencia T-450A/13 [4.5.3].

57 En general, sobre la reclasificación de género en la jurisprudencia constitucional colombiana, véanse Espinosa Pérez (2008: 68) y Moreno Pabón (2014: 123).

58 CC, Sala Séptima de Revisión, 3 de agosto de 1994, Sentencia T-504/94, [4].

59 Decreto Ley de 27 de julio de 1970, no 1260, arts. 89 y 95, disponible en: https://bit. ly/2VR7z0q.

60 CC, Sala Séptima de Revisión, 3 de agosto de 1994, Sentencia T-504/94, [2].

61 CC, Sala Primera de Revisión, 13 de febrero de 2015, Sentencia T-063/15. Tras esta decisión, el presidente de Colombia promulga un decreto (Decreto 1227, de 4 de junio de 2015, art. 2.2.6.12.4.5 [disponible en: https://bit.ly/39zSGDU) que establece un procedimiento notarial, no judicializado ni medicalizado, para el reconocimiento del nuevo género, sin requerir más evidencia a favor de la reclasificación que 
La sentencia de 2015 (T-063/15) hunde sus raíces en la jurisprudencia previa de la Corte en materia de intersexualidad, basada, en gran parte, en la teoría crítica de género. Es en el año 1995 cuando la Corte Constitucional decide su primer caso en materia de intersexualidad, rechazando los tratamientos tempranos de reasignación practicados a bebés intersexuales ${ }^{62}$. Al hacerlo, la Corte aclara que «el sexo representa una característica personal no modificable» por parte de actores externos, siendo únicamente el sujeto «quien, con pleno conocimiento y después de recibir la información adecuada, puede consentir a [su propia] reasignación ${ }^{63}$. Para la Corte, la identidad de género se asienta en la dignidad humana (art. 1 de la Constitución), que abarca también la autodeterminación de la persona, es decir, la autonomía de cada cual para ser el o la única responsable de sus propias decisiones y del curso de su vida ${ }^{64}$. Unos años más tarde, la Corte Constitucional vería la necesidad de proteger a niños y niñas intersexuales de tratamientos normalizadores que podían resultar extremadamente peligrosos para su salud, tanto psicológica como física, ambas tuteladas por el art. 44 de la Constitución ${ }^{65}$. Celebrando la diversidad sexual y apoyándose en la teoría crítica de género, la Corte insistiría en el origen cultural del género y denunciaría que bajo los tratamientos a personas intersexuales subyacía la "construcción» de que solo existen dos géneros claramente definidos $^{66}$. Sería esta crítica a todas las formas de normalización física la que prepararía el terreno para disociar el género legal de la anatomía física y acabaría avalando las pretensiones de las personas trans.

Es así como en el año 2012, en una sentencia que confirma la obligada financiación pública de los tratamientos de reasignación de género ${ }^{67}$, la Corte retoma y ahonda en las nociones de dignidad y también en el derecho al libre desarrollo de la personalidad (art. 16 de la Constitución), entendiendo que este garantiza a cada persona la posibilidad de desarrollar y hacer realidad un proyecto de vida autónomo, sin coerción, controles injustificados u otras

la declaración jurada del demandante (art. 2.2.6.12.4.4). Contempla, además, la posibilidad de una transición de regreso al género «original», aunque limita dicha opción estableciendo un marco temporal (no se permite una transición inversa antes de que transcurra un período de diez años) y restringiendo el derecho a ser reclasificado a un total de dos veces (art. 2.2.6.12.4.6.).

62 CC, Sala Séptima de Revisión, 23 de octubre de 1995, Sentencia T-477/95.

63 Ibid., [13.1].

64 Ibid., [13.2].

65 CC, Sala Plenaria, 12 mayo 1999, sentencia SU-337/1999.

66 Ibid., [II.36].

67 CC, Sala Quinta de Revisión, 8 noviembre 2012, sentencia T-918/12. 
limitaciones más allá de las que nacen de los derechos de otras personas o del interés público ${ }^{68}$. Sostiene la Corte que la dignidad y el derecho al libre desarrollo de la personalidad sustentan la autodeterminación sexual, en un «proceso autónomo de aceptación de la propia sexualidad» sin interferencia o supervisión por parte del Estado, que carece de competencias en la materia ${ }^{69}$, en la medida en que no se derivan posibles daños a terceros ${ }^{70}$. El rechazo a una concepción patologizadora de las personas transgénero se hace de esta forma explícito. Citando literalmente, «[d]e ninguna manera [puede considerarse] la condición trans como una condición patológica o psiquiátrica [que requiere] un diagnóstico de disforia de género para acceder a los servicios de atención médica que están relacionados con la identidad $»^{71}$. El derecho a la salud busca el bienestar del individuo en sentido amplio ${ }^{72}$ y requiere la financiación pública de los tratamientos relacionados con las características sexuales primarias o secundarias que se quieran alterar ${ }^{73}$. Con todo, la decisión de 2012 no da el paso definitivo y no sanciona aún la tesis de la clasificación de género puramente electiva, al avalar la necesaria intervención del juez certificador sobre la base de la evidencia del cambio psicológico y/o físico experimentado por la persona. Y no lo hace porque entiende que el estado civil de la persona (relacionado con el derecho de cada persona a ver reconocida su personalidad jurídica bajo el art. 14), incluyendo el rasgo del género, determina su posición legal en la familia y la sociedad, así como su capacidad legal para disfrutar de determinados derechos y deberes, razón por la cual, entiende, no cabe obviar la naturaleza fáctica del sexo de las personas que el juez debe certificar ${ }^{74}$.

La contradicción interna que esconde el razonamiento de la sentencia del ańo 2012 (T-918/12) no pudo sostenerse en el tiempo: afirmar que el Estado no tiene competencias para determinar la identidad individual (incluyendo la identidad de género), que el género es en gran medida una construcción cultural y que la existencia y el reconocimiento de las identidades trans no implican dańo a terceros entra claramente en conflicto con la interpretación del género como un hecho objetivo que puede y debe certificarse externamente. Es así como las semillas dogmáticas plantadas en la decisión de 2012 fructificarían por fin en la histórica sentencia del año 2015 (T-063/15), que

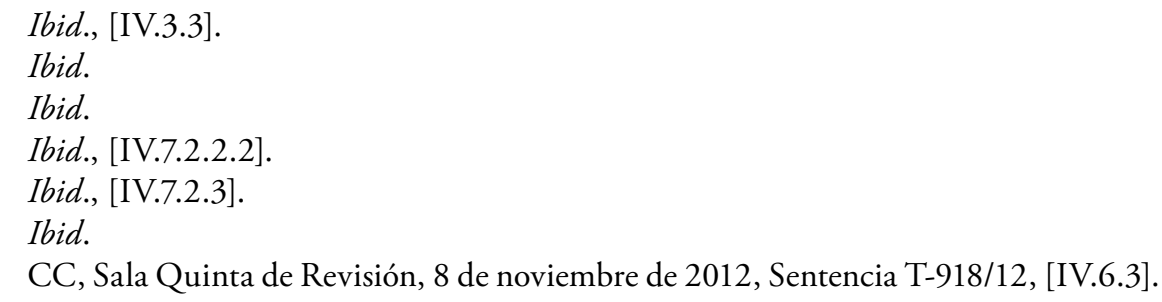


establece finalmente la base constitucional para un sistema de clasificación de género puramente electivo ${ }^{75}$. Efectivamente, es en esta sentencia en la que el Tribunal considera superada la concepción de la identidad sexual como un atributo "objetivo" que viene determinado por la genitalidad y aboga por la adscripción de manera autónoma de cada persona, adscripción que solo corresponde a las autoridades estatales y al resto de la sociedad reconocer y respetar ${ }^{76}$. Además de los inconvenientes del procedimiento judicial hasta entonces seguido (incluyendo su duración, costes e indeterminación) ${ }^{77}$, el problema de raíz, afirma la Corte, es el intento por «objetivizar» la identidad de género, pues cualquier evaluación externa requiere necesariamente un examen físico o psicológico, así como una evaluación de las características generalmente asociadas a un género u otro, todo lo cual implica una restricción innecesaria de la identidad individual en perjuicio de las personas transgénero, a quienes se les obliga «a auto-ubicarse en un extremo heteronormativo, para poder obtener un resultado positivo que permita su reconocimiento", lo cual en muchos casos implica que tengan que «mentir sobre su vida, sus gustos y preferencias y otros muchos aspectos de su personalidad $»^{78}$. Por eso, aunque la Corte no deja de entender que asegurar que no haya cambios arbitrarios del estatus civil de las personas es un objetivo válido, es necesario dar con los instrumentos menos invasivos de la autonomía individual, como el procedimiento notarial basado en la autoidentificación ${ }^{79}$, sin perjuicio de que, en caso de considerarlo necesario, el notario pueda siempre requerir más pruebas, siempre y cuando lo haga sin patologizar o cuestionar la identidad de género autodeclarada de la persona. Según la Corte, dichas pruebas podrían incluir, aunque no de manera necesaria, una declaración jurada del solicitante; declaraciones por parte de dos testigos familiarizados con la persona solicitante que confirmaran su transición, y evidencias de un cambio de nombre anterior o tratamiento médico en caso de que se hubieran llevado a cabo. No obstante, ni los tratamientos médicos ni el cambio de nombre previo podrían considerarse requisitos necesarios para la reclasificación ${ }^{80}$.

En resumen, el sistema colombiano ha pasado de ser un sistema de clasificación por heteroasignación, en el que el género debía ser certificado por un juez mediante examen previo y sobre la base de pruebas materiales, a un

\footnotetext{
CC, Sala Primera de Revisión, 13 de febrero de 2015, Sentencia T-063/15.

Ibid., [II.7.2.4].

Ibid., [II.7.2.5-7].

Ibid.

Ibid., [II.7.2.6].

Ibid., [II.7.2.7].
} 
sistema electivo basado en la autoadscripción del individuo. El modelo colombiano no requiere grado alguno de reconocimiento médico o de otro tipo aunque el Estado se mantiene, hasta la fecha, dentro del binario de género y defiende la necesidad de las categorías de género que considera aún esenciales para la consecución de algunos fines constitucionales y de interés público (incluso después de haberse reconocido el matrimonio homosexual), incluyendo la lucha contra la discriminación de las mujeres ${ }^{81}$. La solución adoptada en Colombia implica privilegiar la libertad y la autonomía individual por encima de cualquier motivo que pudiera justificar vigilar las fronteras de las categorías de género según criterios objetivos. Al reconocer la autoadscripción a través del registro notarial como un modo adecuado y proporcionado de alcanzar el interés público que justifica la preservación de las categorías de género, se acepta que la preocupación en torno a una posible confusión (o fraude) que encontramos en otras jurisdicciones que exigen procedimientos más onerosos es insignificante en comparación con la importancia de afirmar incondicionalmente el derecho a la identidad individual. El género, en cuanto que categoría legal, se mantiene, pero su contenido se convierte en algo abierto que impide deducir de determinados cuerpos o comportamientos definiciones normativas de feminidad y masculinidad.

\section{MANTENIENDO LA ELECCIÓN, SUPERANDO EL BINARIO Y AÑADIENDO FLUIDEZ: EL CASO BELGA}

Con fecha reciente, el procedimiento de cambio de sexo hasta ahora abordado de forma exclusiva en sede legislativa en Bélgica ha acabado siendo causa de litigio constitucional ${ }^{82}$. Objeto del recurso lo constituye la ley de 25 de junio de 2017 de reforma de los regímenes relativos a las personas transexuales en lo que concierne a la modificación del sexo en el registro civil y sus efectos, ley que, a su vez, introducía modificaciones en el Código Civil, la ley del poder judicial y en la ley de nombres. En concreto, la ley de 25 de junio de 2017 venía a modificar el régimen impuesto por la ley sobre transexualidad de 10 de mayo de $2007^{83}$, que había previsto un mecanismo administrativo en

81 CC, Sala Segunda de Revisión, 16 de julio de 2013, Sentencia T-450A/13, at [4.5.3].

82 Cour Constitutionelle, (n. 3).

83 Loi réformant des régimes relatifs aux personnes transgenres en ce qui concerne la mention d'une modification de l'enregistrement du sexe dans les actes de l'état civil et ses effets du 25 juin 2017, disponible en: https://bit.ly/2VT0FYI. Véase Bribosia y Rorive (2018). 
función del cual la persona que solicitaba el cambio debía estar en condiciones de probar su identificación permanente e irreversible con el nuevo género, exigiendo la realización de las cirugías necesarias y de la esterilización. Se trataba, pues, de superar las carencias de este régimen atendiendo a los nuevos estándares internacionales y a los reclamos de los colectivos afectados altamente críticos con la regulación. De hecho, tales colectivos fueron consultados por el Gobierno en el proceso de elaboración de la ley de 2017, logrando que algunas, aunque no todas, de sus pretensiones quedasen recogidas en la nueva regulación.

La nueva regulación, fundamentalmente inspirada en el régimen de la autodeterminación, trata a su vez de garantizar el consentimiento informado y el convencimiento profundo de la persona afectada, así como de evitar la posibilidad de fraude. Así, el art. 3 de la ley de 25 de junio de 2017 prevé que la persona interesada presente una declaración ante el encargado del registro civil haciendo constar su convicción de que el sexo que figura en la partida de nacimiento no corresponde con el de su fuero interno y que es consciente y acepta las consecuencias administrativas y jurídicas que se han de derivar del cambio de sexo. Corresponde entonces al encargado del registro civil indicarle a la persona interesada el carácter en principio irrevocable de la modificación, detallar las consecuencias que se han de derivar de este, y transmitirle por escrito la información relevante, indicándole la existencia de organizaciones de colectivos trans a las que pueda acudir para mejor información. Entre tres y seis meses después de la primera declaración corresponde al solicitante presentar una nueva declaración en la que de nuevo haga constar su identificación con el otro sexo, el conocimiento de los efectos que se han de derivar del cambio, así como la aceptación del carácter, en principio, permanente de su transición. A partir de ahí solo cabe solicitar un nuevo cambio de sexo en supuestos muy excepcionales, pero el procedimiento es más oneroso y requiere la intervención del juez de familia. La normativa cuestionada prevé, además, la obligación que tiene en todo caso el encargado del registro de informar del procedimiento al Ministerio Fiscal a fin de que, en caso de fraude o amenaza al orden público, pueda oponer resistencia, quedando lógicamente abierta la vía del recurso. En sintonía con lo anterior, la ley recurrida prevé la posibilidad de cambio de nombre mediante una simple declaración con base en la discordancia entre el sexo que aparece en el acta de nacimiento y la identidad sentida del solicitante. Con todo, a fin de evitar los cambios múltiples, la ley prevé que el cambio de nombre por este motivo solo pueda realizarse una vez siendo necesaria la intervención judicial que autorice un nuevo cambio en la partida de nacimiento para que, a su vez, pueda solicitarse un cambio ulterior de nombre por motivo de identidad sexual. 
Es esta la legislación objeto de recurso de inconstitucionalidad que plantean tres organizaciones no gubernamentales (Çavaria, Maison Arc-en-Ciel, and Genres Pluriels), recurso que se articula en torno a dos pretensiones centrales $^{84}$. Por un lado, se critica la opción del legislador de hacer que el cambio de sexo en el registro sea en principio irreversible, así como que solo se pueda solicitar una vez, como norma general, el cambio de nombre con base en la identidad trans. Por otro, se aduce que el nuevo sistema no contempla el reconocimiento de las identidades de género no binarias. En definitiva, se argumenta que la ley discrimina tanto a las personas que no tienen una identidad binaria como a las que tienen una identidad fluida de género al dejarlas sin posibilidad de afirmar su identidad de género.

En su sentencia, la Corte da la razón a los recurrentes. Partiendo de una lectura de la constitución belga a la luz de la jurisprudencia del $\mathrm{TEDH}^{85}$, la Corte reconoce que el derecho a la identidad de género está amparado por el derecho a la vida privada y familiar (art. 22 de la Constitución belga). Con respecto a la sexualidad no binaria, la Corte reconoce que, efectivamente, una vez que se acepta que el principio de autodeterminación, debe ser el principio rector en la materia, no se puede dejar de reconocer la existencia de identidades no binarias, sin que el hecho de que hacerlo requiera introducir ajustes en el ordenamiento jurídico, de otra forma basado en el rasgo binario, sea justificación suficiente para denegar el derecho en cuestión ${ }^{86}$. Tampoco cree la Corte que el hecho de que el texto constitucional reconozca las categorías de hombre y mujer cuando prohíbe la discriminación y sanciona la igualdad de derechos entre hombres y mujeres (arts. 10.3 y 11 bis) deba interpretarse como que las categorías de "hombre» y «mujer» sean reflejo del binarismo como rasgo basilar del ordenamiento constitucional belga que impidan la adopción de medidas para luchar contra las diferencias de trato con base en una identidad de género no binaria. Entiende por ello la Corte que se produce discriminación cuando, contrariamente al principio de autodeterminación que es el que, por lo demás, el legislador reconoce como central en la reforma, a las personas de identidad binaria no se les permite la modificación de la identidad recogida en la partida de nacimiento y por ello que se vulneran los arts. 10 y 11 de la Constitución belga. Cuestión distinta es que corresponda al legislador decidir cómo quiere corregir la inconstitucionalidad detectada de acuerdo con la solución que estime más oportuna entre las que cabe la de crear categorías

84 Cour Constitutionelle (n. 3).

85 Entre otras, la Corte cita las sentencias A. P. Garçon et Nicot c. France, de 6 de abril de 2017, y S.V. c. Italie, de 11 de octubre de 2018.

86 Cour Constitutionelle, (n. 3) [B.6.6]. 
adicionales de género, pero también la de suprimir el registro del sexo o de la identidad de género como elemento relevante del estado civil de todas las personas $^{87}$.

Por lo que respecta a la pretensión que problematiza el hecho de que en principio los cambios en el registro sean irreversibles y de que solo se pueda cambiar una vez de nombre por razón de identidad trans, vuelve a darse, entiende la Corte, una discriminación de las personas con identidad de género fluida, quienes pueden encontrarse, en caso de que su identidad evolucione en el tiempo, con una identidad que no corresponda a su fuero interno, cosa que no afectaría a aquellos con identidades binarias o no fluidas ${ }^{88}$. Por lo demás, entiende la Corte que el legislador ha previsto mecanismos para evitar el fraude a través de la participación del Ministerio Fiscal en el proceso sin que se alcance a entender por qué estos no son suficientes para prevenir cualquier tipo de fraude habida cuenta de que dicho Ministerio sería en todo caso conocedor de que se trata de un cambio adicional ${ }^{89}$. Además, habida cuenta de las obligaciones que acompañan al procedimiento (el tiempo obligatorio de reflexión y las medidas para garantizar que el sujeto haya sido debidamente informado), no parece que el carácter en principio irrevocable de la modificación guarde proporción razonable con respecto a la finalidad de evitar que las modificaciones de sexo y nombre se puedan solicitar a la ligera ${ }^{90}$. Con respecto al argumento de la indisponibilidad del estado de las persona aducido por la parte recurrente, entiende el tribunal que el legislador ha atemperado de forma significativa ese principio precisamente para permitir que las personas puedan modificar el género reconocido en el acta de nacimiento, por lo que no tendría sentido privar de esta opción a las personas cuya identidad sea fluida ${ }^{91}$, sin que la posibilidad de obtener remedio por vía excepcional ante el tribunal de familia compense dicha discriminación ${ }^{92}$.

\section{CONCLUSIONES}

En resumen, vemos que Italia cuenta con un largo historial constitucional en el que el sistema de clasificación de las identidades de género, que se
Ibid., [B.7.3].
Ibid., [B.8.1].
Ibid., [B.8.4].
Ibid., [B.8.5].
Ibid., [B.8.6].
Ibid., [B.8.7]. 
ha mantenido binario y por heteroasignación, se ha justificado fundamentalmente en el interés constitucional por preservar la seguridad jurídica y la estructura de la familia heterosexual. La India ha reconocido constitucionalmente la existencia de un tercer género en un caso histórico que, además de no borrar de forma automática los muchos rasgos binarios que siguen presentes en el ordenamiento, sigue aceptando que las identidades sean hasta cierto punto heteroasignadas, en su preocupación por producir un sistema de certificación que evite posibles fraudes. El sistema dice mantener y ampliar las categorías de género no solo en pos de intereses públicos de la sociedad en general, sino también en aras de los derechos fundamentales de las propias minorías afectadas, a quienes reconoce como víctimas de una larga historia de discriminación, y, en calidad de tales, merecedoras de protección especial al amparo del texto constitucional. De esta forma, Italia y (aunque en menor medida) la India se basan en un sistema de certificación externa del género de las personas, centrado en las características físicas y/o psicológicas específicas (de tipo corporal o comportamental) que se esperan de cada género. Colombia, que cuenta con una jurisprudencia constitucional en materia de reclasificación de género excepcionalmente rica, constituye un sistema que, sin renunciar a la categorización del sexo desde un punto de vista jurídico y al rasgo binario, cuenta con un sistema de clasificación puramente electivo basado en el autoentendimiento de cada persona. Solo Bélgica, tras su reciente litigio constitucional, ha dado el paso de exigir que el sistema de clasificación de género debe dar igual acomodo a las identidades no binarias y fluidas para no discriminar en el reconocimiento del derecho fundamental a la identidad de género de todos sus ciudadanos.

A pesar de las notables diferencias que persisten entre estas jurisdicciones, en general, la evolución en cada una de ellas representa una ruptura considerable con la concepción tradicional del sexo/género como hecho dado e inmutable y muestra cómo los derechos fundamentales pueden conducir a un reconocimiento de la identidad de género capaz de transformar de manera significativa el sistema de categorización. En todos los países analizados, el género adscrito en el momento del nacimiento ha dejado de ser inmutable, en mayor o menor medida, y al colectivo trans le ha sido reconocido el derecho a la reclasificación con base en derechos y principios constitucionales como la dignidad, la autonomía, el libre desarrollo de la personalidad, la igualdad, la libertad de expresión o la salud.

Puede que el giro hacia la subjetividad y la fluidez se convierta en una tendencia constitucional más generalizada a medida que se vaya afirmando en más sistemas constitucionales el derecho a la identidad de género. Es además probable que esta conquista se vea facilitada en muchos escenarios por la 
conquista del matrimonio igualitario y, por ende, por el decaimiento de la familia heterosexual como razón central para preservar el sistema binario tradicional. No sería de extrañar que en este camino evolutivo los sistemas de clasificación de género atravesaran una serie de fases graduales desde un modelo que niega la posibilidad de reclasificación (en el que el concepto «biologicista» del género hace del género asignado en el momento del nacimiento algo fijo e inmutable), pasando por un sistema de clasificación condicional y por heteroasignación (basado en una definición preestablecida del género asociada a la transformación física de las características sexuales primarias y/o secundarias, a las características comportamentales o a la certificación de patologías psicológicas), seguidamente, por el desafío gradual de las condiciones específicas para la reclasificación de género a medida que vayan siendo consideradas incompatibles con distintos derechos fundamentales, para desembocar, posiblemente, en la adopción de un sistema de clasificación de género puramente electivo. A su vez, es posible que la evolución parta, en este sentido, de una elección confinada al binario y a la rigidez, para ir progresando hacia sistemas no binarios y fluidos. Como hemos visto, las jurisdicciones analizadas en este artículo se encuentran en distintos puntos de este camino evolutivo, camino que en todos los casos se ha visto condicionado por la intervención de cortes constitucionales y tribunales supremos interpretando derechos fundamentales. Otros países pueden recorrer caminos similares por la vía legislativa ordinaria y seguramente lo harán inspirados por la práctica de países vecinos y por la evolución de los estándares de derechos humanos en la materia, también en rápida evolución.

En todo caso, conviene resaltar que el creciente reconocimiento constitucional del derecho a la identidad de género, especialmente cuando el sistema sigue basándose en la heteroasignación, no implica que el Estado haya cedido el control sobre las categorías de género. En Italia, y en menor media en la India, la reclasificación de género es condicional y sigue dependiendo de los procedimientos de supervisión, transformación y control que la legislación especifica. Incluso el sistema electivo colombiano exige a los solicitantes una declaración jurada para conseguir la reclasificación y regula los tiempos y restringe las veces que pueden hacerse las posibles reclasificaciones. Sea como fuere, las clasificaciones legales de género se han mantenido en todos los casos (aunque la Corte belga abre la puerta a que el sexo de la persona deje de considerarse dato relevante a efectos del registro civil), y a las personas se nos sigue exigiendo que nos identifiquemos y registremos en una de las alternativas ofrecidas, sean estas binarias o ternarias, fluidas o rígidas. En otras palabras, hasta la fecha el derecho constitucional a la identidad de género no parece abarcar plenamente la dimensión negativa que cubriría el derecho a no ser 
sujeto legalmente a ninguna clasificación de género. Antes bien, los distintos ordenamientos constitucionales parecen mayoritariamente reconocer que el sistema de clasificación legal basado en el sexo/género de las personas y el propio criterio en función del cual se categoriza a cada individuo como perteneciente a un género $u$ otro resultan de un equilibrio entre distintos derechos y principios constitucionales, así como de su posible limitación en aras de la salvaguardia de intereses públicos merecedores de protección constitucional.

Con todo, la batalla por el reconocimiento de los derechos fundamentales de las personas trans ha contribuido a problematizar la categorización con base en el sistema sexo/género, cuestionando clasificaciones cuyas razones se han dado históricamente por sentadas. Se consigue así demostrar que, lejos de ser una representación de una realidad "natural» plasmada en registros civiles, o una colección taxonómica de información, las categorías de género pueden ser articuladas como instrumentos para la consecución de determinados fines constitucionales. Además, el análisis constitucional del alcance y los límites del reconocimiento de la identidad de género muestra cómo, a medida que los derechos fundamentales van afirmando su potencial transformador y ampliando las fronteras de las categorías de género predeterminadas, es el propio mecanismo de categorización y su supervisión el que está siendo desafiado. Parecen así confirmarse las tesis de Butler (1999), de acuerdo con las cuales el género difícilmente puede reducirse a las categorías de masculinidad o feminidad, o incluso a la de un tercer género. Se trata más bien de un mecanismo de creación y control normativo, capaz de adoptar distintas formas, binarias y no binarias. Mientras que los mecanismos de clasificación binarios tienden ciertamente a excluir a "personas no binarias", a quienes se las fuerza a encajar en identidades masculinas o femeninas, la introducción de un tercer género sigue teniendo el potencial de excluir a personas que no encajen, siempre que las clasificaciones no binarias también descansen en la objetivación del género a través de criterios preestablecidos y externamente certificables.

Así, vemos que tanto en Italia como en la India lo que opera es un mecanismo generador del género basado en la cooperación entre la medicina y la ley- que da lugar a conclusiones materiales distintas (clasificaciones binarias versus ternarias), pero que, en ambos casos, acaba sometiendo las identidades que no encajan a los poderes normalizadores en un intento por hacer que los sujetos sean «inteligibles» en términos de género. Colombia ha dado un gran paso hacia la desarticulación de la categoría de género en su apuesta por la autodeterminación, si bien no mediante el abandono completo de la categoría misma, sino mediante el desafío al protagonismo del aparato médico-legal que en otros países sigue llenando las nociones de masculinidad y feminidad 
de contenido normativo. Bélgica ha aceptado la autodeterminación y exigido que, para ser plena, se abandonen también el binarismo y la rigidez en tanto que discriminan a las identidades no binarias y fluidas. Pero el sexo/género, como categoría legal, se ha seguido manteniendo y se sigue percibiendo, por regla general, como categoría necesaria para la consecución de fines constitucionales. No es claro que esto siga siendo así, indefinidamente. Por el contrario, puede ser que en el imperativo constitucional de añadir más libertad de elección, más categorías entre las que elegir, y más fluidez y subjetividad al contenido de las elecciones, estemos vislumbrando el inicio de la supresión del género en cuanto que categoría constitucionalmente relevante o que se lo convierta al menos en categoría de clasificación constitucionalmente sospechosa cuyo uso deba superar un estricto test de proporcionalidad que incluya la imposibilidad de otros medios que sirvan para conseguir el objetivo deseado sin necesidad de clasificar a las personas con base en el género. Y puede ser que sea este justamente uno de los miedos que están alentando el populismo de extrema derecha y parte de su retórica, una retórica que parece nutrirse de nostalgia por el orden de género binario, heteronormativo y patriarcal que acompañó al constitucionalismo desde sus albores y que tanto ha limitado la autonomía y la igualdad de quienes lo han experimentado siempre como una imposición violenta.

\section{Bibliografía}

Arroyo Gil, A. (2019). Intersexualidad: Una aproximación jurídica. En F. J. Matia Portilla, A. Elvira Perales y A. Arroyo Gil (comps.). La protección de los derechos fundamentales de las personas LGTBI (pp. 437-488). Madrid: Tirant lo Blanch.

Benavente Moreda, P. (2018). Menores transexuales e intersexuales. La definición de la identidad sexual en la menoría de edad e el interés superior del menor. Revista Jurídica de la Universidad Autonóma de Madrid, 38, 273-316. Disponible en: https:/doi.org/ 10.15366/rjuam2018.38.010.

Bernal Crespo, J. S. (2018). Los derechos fundamentales de las personas transgénero. Cuestiones Constitucionales, 38, 229-245. Disponible en: https://doi.org/10.22201/iij.24484881e. 2018.38.11881.

Boyce, B. (2015). Sexuality and gender identity under the Constitution of India. Journal of Gender Race and Justice, 18 (1), 1-64.

Bribosia, E. y Rorive, I. (2018). Human rights integration in action: making equality law work for trans people in Belgium. En E. Brems y S. Ouald-Chaib (comps.). Fragmentation and integration in human rights law. Cheltenham: Edward Elgar Publishing. Disponible en: https://doi.org/10.4337/9781788113922.00011.

Burgos García, O. (2016). El derecho a la identidad de género como derecho fundamental en interés del menor. En Mujeres e investigación. Aportaciones interdisciplinares: VI Congreso 
Universitario Internacional Investigación y Género (pp. 65-78). Sevilla: Seminario Interdisciplinar de Estudios de las Mujeres de la Universidad de Sevilla (SIEMUS).

Butler, J. (1999). Gender trouble: Feminism and the subversion of identity. London; New York: Routledge.

Cartabia, M. (2011). Avventure giuridiche della differenza sessuale. Quaderni di Iustitia. Nuova Serie, 6, 285-306.

Chakrapani, V. (2012). The case of Tamil Nadu transgender welfare board-insights for developing practical models of social protection programs for transgender people in India. India: United Nations Development Programme. Disponible en: https://bit.ly/2ug8r3w.

Dogliotti, M. (1987). La Corte Costituzionale riconosce il diritto all' identità sessuale. Giurisprudenza Italiana, 161, 235-243.

Dunne, P. (2017). Transgender sterilisation requirements in Europe. Medical Law Review, 25 (4), 554-581. Disponible en: https://doi.org/10.1093/medlaw/fwx028.

(2018). Towards trans and intersex equality: Conflict or complementarity? En J. Scherpe, A. Dutta y T. Helms (comps.). The legal status of intersex persons. Cambridge: Intersentia.

Dutta, A. (2014). Contradictory tendencies: the Supreme Court's NALSA judgment on transgender recognition and rights. Journal of Indian Law and Society, 5 (2), 225-236.

Elvira Perales, A. (2013). Transexualidad y derechos. Revista General de Derecho Constitucional, 17, 1-29.

Encarnación, O. G. (2016). Out in the periphery: Latin America's gay rights revolution. New York: Oxford University Press. Disponible en: https://doi.org/10.1093/acprof:oso/ 9780199356645.001 .0001 .

Espinosa Pérez, B. (2008). Cuerpos e identidades: el transexualismo reta al derecho. En B. Espinosa Pérez (comp). Cuerpos y diversidad sexual. Aportes para la igualdad y el reconocimiento (pp. 68-79). Bogotá: Editorial Pontificia Universidad Javeriana.

García López, D. J. (2015). La intersexualidad en el discurso médico-jurídico. Eunomia, 8, 54-70.

Lauroba Lacasa, E. (2018), Las personas intersexuales y el derecho: posibles respuestas jurídicas para un colectivo invisible. Derecho Privado y Constitución, 32, 11-54. Disponible en: https://doi.org/10.18042/cepc/dpc.32.01.

Lemaitre, J. (2009). El amor en tiempos de cólera. Derechos LGBT en Colombia. Sur. Revista Internacional de Derechos Humanos, 6 (11), 95-97. Disponible en: https://doi. org/10.1590/S1806-64452009000200005.

Loh, J. U. (2018). Transgender Identity, Sexual versus Gender 'Rights' and the Tools of the Indian State. Feminist Review, 119 (1), 39-55. Disponible en: https://doi.org/10.1057/ s41305-018-0124-9.

Lorenzetti, A. (2013). Diritti in transito: La condizione giuridica delle persone transessuali. Milano: Franco Angeli.

- (2018). Il cambiamento di sesso secondo la Corte costituzionale: due nuove pronunce (nn. 180 e 185 del 2017). Studium Iuris, 4, 446-454.

Moreno Pabón, D. C. (2014). Derecho, persona e identidad sexual. El debate jurídico de la documentación de las personas trans. Universitas Estudiantes, 11, 123-143. Disponible en: https://bit.ly/38HNq0y. 
Narrain, S. (2009). Crystallising Queer Politics-The Naz Foundation Case and Its Implications for India's Transgender Communities. National University of Juridical Sciences Law Review, 2 (3), 455-470.

O'Brien, W. (2015). Can international human rights law accommodate bodily diversity? Human Rights Law Review, 15 (1), 1-20. Disponible en: https://doi.org/10.1093/hrlr/ ngu043.

O'Flaherty, M. (2015). The Yogyakarta principles at ten. Nordic Journal of Human Rights, 33 (4), 280-298. Disponible en: https://doi.org/10.1080/18918131.2015.1127009.

Patti, S. (2016). La Corte costituzionale e la "necessità" di interventi medico-chirurgici ai fini dell'attribuzione di sesso. GenIUS, 1. Disponible en: https://bit.ly/2HIunqR.

Pezzini, B. (2010). Il matrimonio same sex si potrà fare. La qualificazione della discrezionalità del legislatore nella sent. n. 138 del 2010 della Corte costituzionale. Giurisprudenza Costituzionale, 3, 2715-2727.

Reddy, G. (2005). With Respect to Sex: Negotiating Hijra Identity in South India. Chicago: University of Chicago Press. Disponible en: https://doi.org/10.7208/chicago/97802 26707549.001.0001.

Rubio-Marín, R. y Osella, S. (2016). Le precondizioni per il riconoscimento dell'identità sessuale. Quaderni Costituzionali, 1, 61-86.

Salazar Benítez, O. (2015). La identidad de género como derecho emergente. Revista de Estudios Politicos, 169, 75-107. Disponible en: https://doi.org/10.18042/cepc/rep.169.03.

Spade, D. (2015). Normal life: Administrative violence, critical trans politics, and the limits of law. Durham; London: Duke University Press. Disponible en: https://oi.org/10.1215/ 9780822374794.

Starr, P. (1992). Social categories and claims in the liberal state. Social research, 59 (2), 263-295.

Voli, S. (2018). "Il parlamento può fare tutto, tranne che trasformare una donna in uomo e un uomo in donna". (Trans)sessualità, genere e politica nel dibattito parlamentare della legge 164/1982. Italia Contemporanea, 287, 75-103. Disponible en: https://doi. org/10.3280/IC2018-287004. 